\title{
O Platão de Deleuze
}

\author{
Deleuze's Plato
}

\section{Rafael Alvarenga Gomes}

Doutorando em Filosofia na UERJ

Resumo: Este artigo pretende investigar o interesse de Gilles Deleuze pela filosofia de Platão. Para tanto, optamos por apresentar, ainda que brevemente, as demarcações sobre as quais Deleuze ergue seu trabalho filosófico. Sendo assim, ideias como as de Espaço, Imagem do Pensamento e Pensamento sem Imagem serão mostradas como alicerces desse empreendimento filosófico. Então, tendo em vista a apresentação de como funciona o procedimento deleuziano, mostraremos o que há no pensamento platônico que interessa a Deleuze, a ponto de chegarmos a afirmar que existe um Platão de Deleuze.

Palavras-chave: Deleuze; Filosofia da Diferença; Platão.

Abstract: This article intends to investigate the interest of Gilles Deleuze by the philosophy of Plato. For this, we chose to present, albeit briefly, the demarcations on which Deleuze arises his philosophical work. Therefore, ideas such as Space, Image of Thought and Thought without Image will be shown as the foundations of this philosophical enterprise. Then, in view of the presentation of how the Deleuze procedure works, we will show what is in the Platonic thinking that interests Deleuze, to the point of stating that there exists a Deleuze's Plato.

Keywords: Deleuze; Philosophy of Difference; Plato. 


\section{Introdução}

Dos livros que escreveu sobre o pensamento de grandes filósofos, Gilles Deleuze não se propôs a dedicar um exclusivamente a Platão ${ }^{21}$. Entretanto, não é possível passar pela filosofia sem ser observado pelo filósofo grego seja por ter criado a metafísica, seja por ter sido o primeiro a privilegiar a identidade. Mas Deleuze não pretende continuar a metafísica platônica, tampouco legitimar a identidade enquanto representação. Ainda assim, em livros como Diferença e Repetição e Lógica dos Sentidos, as questões propostas desde Platão reaparecem. É que Deleuze torce, moe os diálogos e espera deles retirar um caldo original e nutritivo para alimentar seu próprio filosofar.

Filosofia para Deleuze é criação de algo muito específico, conceitos (Deleuze, 1997, p. 57). Quando ele faz essa afirmação se refere a filosofia bem como ao filósofo. Refere-se, portanto, ao exercício do pensamento no âmbito da filosofia, ou seja, nos limites do espaço filosófico. E quanto a Deleuze como ele se situa nesse território? Que seja dada logo a resposta: hasteando a bandeira de uma filosofia da diferença.

Fincar um mastro e hastear uma bandeira são atitudes deleuzianas realizadas no espaço e não no tempo para dizer que"A filosofia é devir, não história;"(Deleuze, 1997, p. 78). Por isso ele escolhe fazer uma geografia do pensamento ao invés de uma história da filosofia. Empenhado nessa tarefa, irá criar um espaço para a filosofia da diferença, ou, como ele mesmo se refere, para o pensamento sem imagem. E é, justamente, com o intuito de produzir a sua filosofia que Deleuze se apropria de idéias platônicas. Tal prática o filósofo realiza também com outros pensadores, como Nietzsche, Spinoza, Bergson, Hume, e até mesmo Kant. A filosofia de Deleuze busca o que há no pensamento e que pode ser usado para construção da filosofia da diferença. É por isso que catará as vantagens das quais necessita também na pintura com Francis Bacon, na literatura com Marcel Proust, no cinema com Jean-Luc Godard. Pois são

$21 \quad$ Livros de G. Deleuze sobre o pensamento de um filósofo: D. Hume (1953); F. Nietzsche (1962 e 1965); I. Kant (1963); H. Bergson (1966) e Spinoza (1968). 
também pensadores, embora não produtores de conceitos, ora uma exclusividade dos filósofos.

Seguindo esse viés, julgamos importante apresentar algumas características da filosofia de Deleuze. Por conseguinte, as divisões do texto tratam, entre outras coisas, de uma geografia (espaços) do pensamento, da imagem do pensamento e do pensamento sem imagem, pois são pilastras desses tantos platôs erguidos por Deleuze. Entretanto não podemos perder de vista o objetivo geral do artigo que é a defesa de que há um Platão de Deleuze. Há um Platão dentro das obras do filósofo francês que é outro, justamente por ser o que há em Platão que interessa à filosofia da diferença. Isso é o que ocorre, principalmente em Diferença e Repetição e Lógica dos Sentidos, onde Platão aparece como motivo de reflexão, seja através das seleções de linhagem, seja através da distinção entre cópia e simulacro, que Deleuze embora denomine como distinção latente, prioriza.

O Platão de Deleuze é, portanto, aquele lhe interessa.

\section{Um problema platônico}

Platão (V a.C. - IV a.C.) viveu em um período democrático conturbado em Atenas, sua cidade natal. No entanto, não resta dúvida de que havia o que comemorar, uma vez que o súdito cedera lugar ao cidadão. A partir de então, as decisões decorriam de um processo de discussão em praça pública e a força passara a pertencer ao diálogo e não mais ao fio amolado da espada da tirania. Ainda assim, havia, por outro lado, o que lamentar como foi o caso da condenação de Sócrates pela mesma democracia. Sobre isso salienta Perine:"[...] a hostilidade dos democratas contra Sócrates estendeu-se também aos seus discípulos [...] Por isso, Platão deixou Atenas depois da morte de Sócrates e só regressou em 387 a.C. para fundar a Academia." (Perine, 2014. P. 43). Ainda que democrática, Atenas não era segura para os filósofos que, entre outras coisas, questionavam o Estado e a maneira como os indivíduos o governavam, primeiramente através de discussões em praça pública e depois com textos escritos, tendo alguns deles, chegado até nós. 
Dentre esses escritos se situa a longa produção filosófica redigida por Platão que está dividida em três fases e remonta a 399 a.C. com os diálogos socráticos ou aporéticos, além dos diálogos da maturidade e os escritos da velhice (Perine, 2014, p. 49). Esses diálogos discutem temas diversos e importantes. É o caso da falsidade (Hípias Menor), da coragem (Laques), da justiça (República), do amor (Banquete), do prazer (Filebo) ou da arte de governar (Político). Nos diálogos Platão faz de Sócrates o personagem principal que interpela seus interlocutores a fim de obter definições conceituais. O que é a falsidade, a coragem, a justiça, o amor, o prazer, a arte de governar? Ou seja, Platão busca uma definição conceitual que se afaste dos exemplos múltiplos e singulares dados pelos sofistas, seus principais inimigos.

Nesse sentido, é possível ainda afirmar que o objetivo de Platão, através tanto de sua estilística literária quanto de seu método, está apontado para separar o sensível do inteligível, a essência da aparência, o imutável do transitório. Tal compreensão, de pronto, atribui a Platão a alcunha de filósofo abstrato e, além disso, apaga toda referência prática que tem o conceito, a Ideia, naquela Atenas democrática, porém instável, do século IV a.C.. Porém, para Deleuze: "O problema filosófico consiste em encontrar, em cada caso, a instância capaz de medir um valor de verdade das opiniões oponíveis, seja selecionando umas como mais sábias que as outras, seja fixando a parte que cabe a cada uma." (Deleuze, 1997, p. 104). Portanto, a Ideia - de justiça, amor, prazer e etc - tem uma função prática: resolver um impasse real dentro daquela sociedade, ou seja, selecionar.

No caso do diálogo Político, sua função é clara, pensar "[...] Na política, onde quem quer que seja pode aspirar ao que quer que seja, na democracia ateniense tal como a vê Platão. De onde a necessidade para Platão de uma reordenação, na qual se criem instâncias que permitam julgar [...]" (Deleuze, 1997, p. 18). Nesse caso, a Ideia, o Modelo, específico do conceito de político, enquanto pastor dos homens (Platão, 276c) precisa de um critério, de uma baliza, uma régua para medição. Isso sugere que há uma questão na democracia que merece sé- 
ria atenção, pois todo cidadão torna-se um pretendente em potencial. Todos eles podem aspirar a uma posição de governança dentro do sistema, sobretudo, na esfera política.

Sem dúvida a hierarquia social ateniense já se havia encarregado de estreitar os candidatos, na medida em que mulheres e escravos eram, por uma condição pré-determinada, impedidos de serem pretendentes. Contudo vejamos o tamanho do problema com o qual Platão se depara! Pensemos naquele que se torna governante, pastor dos homens. Esse pretendente, assim que conquista seu prêmio, passa a fazer da sua voz as determinações legais do Estado; do direito e do dever. Fluxo que culminou com a condenação socrática além de avisada hostilidade para com seus discípulos, dentre os quais, ou principalmente, figurava Platão. Em certa medida, um governante adequado à Ideia, ao Modelo, ainda que abstrato de governante ideal, não teria condenado alguém como Sócrates. Isso significa que um governante mal escolhido ou apontado através de um critério sem rigor seria a causa dos maiores infortúnios à sociedade.

\section{Seleção de linhagens}

Deleuze, por sua vez, se refere ao Modelo criado por Platão como aquilo que quer selecionar linhagens: "[...] dividir uma espécie confusa em linhas puras, ou selecionar uma linhagem pura a partir de um material que não o é." (Deleuze, 2018, p. 66). Portanto, selecionar uma linha, uma ordem de importância, tendo em vista candidatos, pretendentes que não podem ser igualados a Ideia, ao Modelo, enquanto critério. Pois essa era a quentão política urgente na época de Platão. O que mais lhe preocupava era distinguir o mais e os menos preparados: "O objetivo da divisão não é, pois, em absoluto, dividir um gênero em espécies, mas, mais profundamente, selecionar linhagens: distinguir os pretendentes, distinguir o puro e o impuro, o autêntico e o inautêntico." (Deleuze, 1974, p. 260). A qual pretendente se deve entregar o governo dos homens? É com isso que Platão se inquieta. Dessa forma, a produção de seu Modelo, não é uma criação sem conexão com o mundo que o filósofo habitava de corpo e alma. Mundo esse que era palco 
de tiranos e sofistas; de filósofos e sábios; artistas e charlatões; cidadãos e escravos; políticos e demagogos.

Através dos artifícios todos os pretendentes apelam na Atenas platônica. Querem igualmente conquistar. Esse é o motivo pelo qual se travestem, se armam, se aprumam. Entretanto, o prêmio não pode ser atribuído sem um critério. Além do que, apenas um dos pretendentes será o escolhido como pastor dos homens, ou seja, governante. Os outros serão todos reprovados. Não há entre os reprovados um mais capacitado que o outro, porque isso já não mais interessa. Ficam, depois do escolhido, sob o jugo da Ideia, do Modelo, todos relegados a uma mesma categoria: dos impróprios, impuros, inadequados. Pois não pode haver empate, tampouco comiseração. O procedimento é usado por Platão a fim de selecionar.

Os pretendentes desejam participar da Ideia, do Modelo de pastor dos homens. Porém, como só a justiça é justa, nenhum dos participantes pode estar perfeitamente de acordo com o Modelo. Daí resulta que aquele, dentre os pretendentes, que mais participar desse Modelo, enquanto baliza, régua, será escolhido. Isso quer dizer que o que está em jogo aqui, para Platão, é a questão da semelhança. Se não é possível ser tal como a Ideia balizadora é preciso se assemelhar a ela. Para nos expressarmos em uma linguagem platônica podemos usar a seguinte fala do personagem estrangeiro no diálogo Político: "Retomemos então o raciocínio de há pouco: milhares de rivais disputam ao gênero real a honra dos cuidados que ele dispensa às cidades; para bem isolá-los é preciso, naturalmente, separá-los; e para tanto é que dissemos ser necessário um paradigma." (Platão, 279a). Aqui o paradigma é o Modelo, a Ideia. Sem ele não há chance de saber com rigor objetivo quem deve ser o governante.

\section{Cópia e simulacro}

Voltar para Atenas significa então, para Platão, estabelecer os critérios de uma filosofia que se empenhe em distinguir a cópia do simulacro. Tendo a Ideia como Modelo todos os pretendentes ao cargo de pastor dos homens podem ser medidos, 
comparados, selecionados e o resultado, por fim, legitimado sem qualquer questionamento. É nesse sentido, que Deleuze aponta para duas dualidades no sistema filosófico de Platão. A primeira delas denominada dualidade manifesta se refere a uma distinção entre essência e aparência, sensível e inteligível, corpóreo e incorpóreo. Desse modo, separando a realidade em duas - mundo inteligível e mundo sensível - Platão cria a metafísica e subordina o mundo sensível (das sombras, do fundo da caverna) ao mundo das Idéias, das formas perfeitas (Deleuze, 1974, p. 268). Já a segunda, a dualidade latente, é a que mais interessa a Deleuze. Pois sua função é separar a cópia do simulacro. Dessa forma, cópia é aquilo que está bem fundada no modelo, em outros termos, é uma imagem com semelhança. Enquanto que simulacro é a imagem que apresenta diferença, distorção, mudança com relação ao Modelo. Ou seja, em outros termos, o que é próprio do simulacro é a dessemelhança, a diferença.

Aqui está, então, algo da filosofia platônica que será colhido por Deleuze. Um conceito-pedra-bruta que ao sofrer os cortes lapidários adequados é perfeitamente encaixado no projeto deleuziano de erguer o edifício da filosofia da diferença. Pois, segundo o próprio Deleuze: "O simulacro é construído sobre uma disparidade, sobre uma diferença, ele interioriza uma dissimilitude." (Deleuze, 1974, p. 265) Sendo assim, o que o simulacro interioriza é a diferença. Em seu âmago está o que lhe garante o devir, a transformação. Não há, por isso, semelhança, identidade, posto que a transformação ressalta o movimento do devir. $\mathrm{O}$ simulacro não se relaciona com o mesmo. Em seu interior não é o próprio do anterior que reverbera e guia uma re-produção ontológica. É o Outro interiorizado que serve como Modelo para o simulacro que jamais se rende ao Mesmo. Se esse Mesmo é a Ideia, o Modelo platônico, sem dúvida, o simulacro será a parte excluída, rejeitada. No entanto, como Deleuze, por sua vez, não pretende repetir a semelhança e sim a diferença, ele leva consigo, para seu território os simulacros e não as cópias.

Notemos que isso também diz muito sobre a própria Ideia considerada como Modelo. Ele jamais é completamente igualável. É única enquanto medida a ser utilizada a fim de es- 
tabelecer lugar para os pretendentes. O Modelo nunca é outro; nunca é mudança. É uno e permanente. Sua existência é tão singular quanto fundamental. E tão abstrata quanto, na visão de Platão, praticamente útil para as relações de política e poder da democracia ateniense. Como se refere Deleuze: "O modelo platônico é o Mesmo: no sentido em que Platão diz que a Justiça não é nada além de justa, a Coragem, corajosa etc. - a determinação abstrata do fundamento como aquilo que possui em primeiro lugar." (Deleuze, 1974, p. 266). Dizer que somente a justiça é justa, nesse caso, significa afirmar que cada pretendente tem um grau diferente de participação na justiça. Isso, claro, se forem cópias, as únicas aceitas por Platão em razão de guardarem uma semelhança com a Ideia que foi transformada em Modelo. Então, a cópia é aquela que mais participa da justiça, que, por sua vez, deve ser entendida como Ideia, como Modelo. Já os simulacros não participam em nada da justiça.

Essa dualidade latente, que define cópias e simulacros, será usada por Platão como critério na cidade perfeita. As cópias tendo lugar garantido pela semelhança com o Modelo, embora não sendo perfeitas. Enquanto que os simulacros, possuidores apenas da dessemelhança, estariam impedidos de atravessar os pórticos dessa cidade. Estariam excluídos e, usando uma linguagem cristã, excomungados, proibidos de habitar esse lugar ideal que seria a república platônica. Haveria no simulacro uma desenvoltura para desviar-se da semelhança. Uma dissimulação transfigurada em tendência interna para fazer submergir outra e outra máscara capaz de mostrar o simulacro sempre diferente, jamais em consonância e semelhança com o Modelo.

Então, se a cópia guarda uma semelhança com o Modelo é justamente disso que o simulacro foge, pois ele não guarda nenhuma paridade. Não há nada que subsista nele. Nenhum fundo secreto a ser revelado. Seu movimento é uma transformação, destruição e criação incessante: "Em suma, há no simulacro um devir-louco, um devir subversivo das profundidades, hábil a esquivar o igual, o limite, o mesmo ou o semelhante: sempre mais e menos ao mesmo tempo, mas nunca igual." (Deleuze, 1974, p. 264). O simulacro não para. A transformação 
é seu devir, ou seja, é a maneira como se apresenta ao mundo. Um devir interior que o faz jorrar de dentro de si mesmo em uma sucessão de máscaras. Por esse processo o simulacro jamais é enjaulado pela representação.

Para Platão, a relação que legitima as cópias e que deslegitima os simulacros, interessa tanto no campo de sua metafísica quanto na ágora onde a política ateniense é debatida. No que diz respeito a Deleuze, seu interesse recai sobre o simulacro e sua natureza cultivada no interior da diferença.

\section{Geografia do pensamento: abrindo espaços}

Não importa quando - do ponto de vista histórico - um conceito foi criado, e sim quais são e onde estão os problemas que ele busca resolver. O projeto filosófico de Deleuze se faz a partir de um viés geográfico. É, portanto, o espaço e não o tempo do pensamento que mais interessa (Deleuze, 1992, p. 132). Tratando-se então de uma geografia os espaços demarcados, assim como os conceitos, são criados, para depois serem expandidos ou retraídos, ocupados ou esvaziados. Ou seja, isso significa que não há qualquer coisa subjacente; casta ou essencial que precise ser descoberta por aquele - o filósofo - em seu processo de purificação onde ele se tornaria melhor. O filósofo, assim, não é o escolhido; é, sim, um criador que ao criar conquista. É aquele que escolhe fazer, inclusive fazer ruir se assim for preciso para reerguer seus territórios, seus conceitos, sua filosofia. E aqui podemos, inclusive, citar Nietzsche que debocha de uma filosofia produzida antes da sua onde "Ainda não se fazia distinção entre "descobrir" e "inventar"” (Nietzsche, 2006, p. 17). $\mathrm{O}$ alvo aqui é Kant e o conceito de imperativo categórico. De acordo com Nietzsche, Kant não descobriu o conceito, ele o inventou. E é daqui que Deleuze, leitor voraz de Nietzsche, tirará a inspiração para uma filosofia enquanto criação de conceitos, planos e espaços; de um pensamento, sobretudo, geográfico.

É ainda baseado em Nietzsche, que Deleuze irá duvidar de Platão, que antes de tudo, toma a forma de uma bússola, de um oráculo santificado, diante do qual não há quem possa vacilar. A 
metáfora platônica do pensamento e suas linhas de ascensão ou degenerescência sempre foram irretocáveis no mapa do pensamento ocidental. Platão, e a Ideia apontam o norte. Mas, frente a esse altar, Deleuze se mostra incomodado com o habitual:

Quando perguntamos "Que é orientar-se no pensamento?" aparece que o pensamento pressupõe ele próprio eixos e orientações segundo as quais se desenvolve, que tem uma geografia antes de ter uma história, que traça dimensões antes de construir sistemas. A altura é o oriente propriamente platônico. A operação do filósofo é então determinada como ascensão, como conversão, isto é, como o movimento de se voltar para o princípio do alto do qual ele procede e de se determinar, de preencher e de se conhecer graças a uma tal movimentação. (Deleuze, 1974, p. 132)

Se o que interessa para Deleuze é uma geografia do pensamento, então são as noções de dimensão, eixos e altura, bem como os movimentos de ascensão e conversão que ele irá procurar em Platão, para, usando esse procedimento de busca, criar o seu Platão. Um filósofo que cria uma orientação para o pensamento; ordenando-o com o intuito de mostra-lhe a direção correta. Não é por acaso, que Deleuze enxerga no movimento de subida do filósofo que sai do fundo escuro da caverna, uma orientação, antes de tudo geográfica. O filósofo platônico é aquele que pode se aproximar da Ideia, do Modelo. Ele é quem pode usar esse critério a fim de escolher corretamente, por exemplo, quem será o governante.

Platão mostra a direção e cria, segundo os termos deleuzianos, o espaço da representação. Além disso, como expulsa e esconjura a diferença, deslegitima também um espaço para ela. A diferença deve ser apagada enquanto a orientação platônica do espaço do pensamento vigorar unânime. A metafísica e suas dualidades (Nietzsche, 2006, p. 10) não oferecem rota alternativa. Não oferecem estrada para além do bem e do mal. Seguir para baixo, para as sombras, já foi duramente condenado por Platão, o primeiro grande orientador da direção correta do pensamento.

Mas Deleuze enxerga para além do matagal que margeia a estrada. Percebe que a diferença não foi decapitada, apenas subjugada a identidade. Portanto, ela existe. E Platão sabia 
que não podia livrar o mundo dela. Por isso, cria Modelos que a deslegitime. A diferença persiste. Camuflada no matagal; travestida de flor; afiada em espinho. E é para essa diferença que Deleuze se propõe a abrir espaços novos. Um espaço para a filosofia da diferença. Um espaço com uma orientação contrária àquela criada por Platão. A um tempo, o Platão de Deleuze é aquele que tentando esconder, mostra o simulacro.

O que Deleuze propõe é a criação de um espaço para a sua filosofia que é sem igual. Sobretudo por se basear na heterogeneidade, no caos e na diferença já que: "Para falar do simulacro, é preciso que suas séries heterogêneas sejam interiorizadas no sistema, compreendidas ou complicadas no caos, é preciso que sua diferença seja incluída" (Deleuze, 1974, p. 268). Incluir a diferença é, por natureza, um procedimento de resistência; uma atividade de afirmação como outra possibilidade diante da filosofia da representação, da metafísica, da imagem do pensamento que se orientam sempre a partir da exclusão da diferença e do que é diferente. Deleuze, ao contrário, pretende incluir a diferença, afirmá-la. Motivo, então, suficiente para ter criado, em seu projeto filosófico, um espaço para a filosofia da diferença, para o pensamento sem imagem, para o devir, para a repetição do Outro. É por isso, que em se tratando de Deleuze, entramos em uma geografia do pensamento.

\section{A Imagem do Pensamento e o Pensamento sem Imagem}

Os dois espaços criados são o da imagem do pensamento, sustentado pela representação, ou seja, pela identidade; e o do pensamento sem imagem, ao qual corresponde a diferença. Nesses espaços Deleuze agrupa tanto conceitos, quantos filósofos, e, no caso da imagem do pensamento, os fenômenos são congelados. De acordo com Cunha: "o pensamento representativo reduz a multiplicidade à identidade." (Cunha, 2003, p. 56). Em seguida comunica os fenômenos como formas universalizantes, as quais poderiam ser reconhecidas e afirmadas no tempo com legitimidade. Trata-se aqui do processo de recognição. Um estabelecimento cordial entre faculdades cavalheirescas e honradas nas quais o "Eu" poderia confiar ainda que em tempo futuro. 
"A recognição se define pelo exercício concordante de todas as faculdades sobre um objeto suposto como sendo o mesmo: é o mesmo objeto que pode ser visto, tocado, lembrado, imaginado, concebido..." (Deleuze, 2018, p. 131). A recognição supõe uma identidade entre o que o fenômeno apresentou e aquilo que chegou até a sensibilidade. Ora, isso é também o processo de estabelecimento e garantia de verdade ou falsidade de uma proposição. Quanto mais fiel à recognição, ou seja, à representação, maior o nível de verdade atribuída à proposição.

Por isso Deleuze associa a cópia platônica, como exemplo, a uma filosofia da imagem do pensamento; a uma filosofia da representação, da semelhança, da identidade. Pois esses seriam requisitos fundamentais para a legitimação de um pretendente (Deleuze, 1974, p. 262), como ocorre no caso de Platão com a Ideia, o Modelo de "pastor dos homens". O filósofo grego está interessado, exclusivamente, nas cópias porque elas é que guardam algum nível de semelhança, identidade com a Ideia, o Modelo. Em razão disso, Platão é posto por Deleuze no território da imagem do pensamento, neste caso, da representação, da identidade. Geograficamente, é lá que mora o Platão de Deleuze.

Entretanto, é no espaço do pensamento sem imagem, neste caso, da diferença, que Deleuze construirá sua filosofia. Nesse território, ele agrupará conceitos e idéias que lhe interessam; tal como um construtor que procura os pedaços de pedra necessários para construir as paredes que está erguendo, Deleuze procura nos filósofos os conceitos que julga importantes para a construção da sua filosofia. Todavia ele busca esses conceitos de forma bruta em outros pensadores. Procura o que o pensador disse para então lapidar esse conceito-pedra-bruta fazendo-o se enquadrar à necessidade do seu projeto particular. É assim que ele repete o que um pensador disse, na medida em que rouba dele o seu pensamento. E aqui há duas implicações. A primeira é que não há uma preocupação moral com o roubo, a apropriação da criação feita por outro. Não há culpa, tampouco assepsia intelectual. Pensar é misturar, por vezes sujar e, sem dúvida, transformar. Em segundo lugar, Deleuze não repete o mesmo. Não rouba o conceito-pedra-bruta a fim de fazê-lo se encaixar 
perfeitamente em sua filosofia sem nele promover o desgaste ou o enxerto de uma interpretação. O conceito-pedra-bruta que Deleuze encontra em outros filósofos, portanto, é repetição da diferença, uma vez que quando é levado para o espaço da diferença já foi interpretado e modificado. Assim, a legitimidade do conceito diz respeito a uma nova interpretação que lhe garante a criação de uma nova existência. Agora oferecendo sua potência para responder a questões novas, ou ainda a antigos problemas, desde que com vistas à criação de novas soluções.

Com o intuito de sustentar seu pensamento Deleuze constrói um território e demarca as fronteiras que o separam da filosofia da imagem do pensamento, da representação. E isso é feito em prol de um pensamento sem imagem, da diferença. Por isso, ler um filósofo, compreender suas idéias e os problemas aos quais está ligado torna-se, um processo de procura, de cata daquilo que interessa para a construção de uma filosofia que quer o dessemelhante. O que há em Platão que é útil a esse empreendimento? Essa é a uma questão central já que Deleuze buscou se aproveitar desse filósofo. Se Platão ocupa uma vaga no território da representação, poderia ser importante para a construção deleuziana? Sim, porque Deleuze não está comprometido em aceitar toda a produção filosofia platônica por qualquer ordem como a moral ou o dever. E sabe que sendo Platão um filósofo da representação ele obriga a diferença a se curvar diante da identidade, que ele coroa como vossa majestade. Por isso, quando Deleuze pensa Platão e se utiliza tanto dos problemas levantados por ele quanto das soluções que elaborou, apresenta a seus leitores, um Platão que já é outro: o Platão de Deleuze.

\section{O Político de Platão de Deleuze}

O interesse pelo Político está no fato de Platão praticar uma seleção. Sua iniciativa ao propor uma Ideia um Modelo é separar, diferenciar, mostrar dessemelhanças, indicar graus de distância. Levando em consideração que seu Modelo se refere a uma ascensão, do fundo da caverna para a luz do Mundo das Ideias, Platão se interessa em fazer os diferentes ocuparem também degraus desiguais em uma escala. É precisamente, 
nesse sentido, que voltando a teoria platônica para o problema vivido pela democracia ateniense dos séculos $\mathrm{V}$ a.C. e IV a.C. encontramos o sentido prático, o objetivo dessa procura infindável por uma Ideia, um Modelo.

No Político notamos que a preocupação platônica se volta para a forma como deve ser escolhido aquele que irá pastorear os homens, ou seja, quem deve ser o governante. Platão, que já vivera a condenação de Sócrates, vê essa escolha política como fundamental para uma sociedade justa. Na democracia todos os cidadãos podem pretender ao governo, todavia um necessita ser escolhido. E isso é possível aceitando a diferença que é medida e legitimada entre eles pela Ideia, pelo Modelo: "Em termos muito gerais, o motivo da Teoria das Idéias deve ser buscado do lado de uma vontade de selecionar, de filtrar. Trata-se de fazer a diferença." (Deleuze, 1974, p. 259).

Platão não quer agrupar. Ao contrário, faz tudo para selecionar, separar a partir da diferença. Dessa forma, pretende, com autoridade e eficiência, separar a cópia dos simulacros. Aquela ocupando o degrau mais alto da escala, ficando o mais próximo possível da Ideia, do Modelo, lugar que lhe é garantido através da semelhança; por outro lado, os simulacros ocupariam, cada qual, um degrau ainda mais inferior e exatamente esse posicionamento implicaria sua exclusão, sua expulsão da república perfeita. Assim se refere Deleuze sobre esse texto de Platão "O Político distingue em detalhe: o verdadeiro político ou o pretendente bem fundado, depois parentes, auxiliares, escravos, até aos simulacros e contrafacções. A maldição pesa sobre esses últimos; eles encarnam a má potência do falso pretendente." (Deleuze, 1974, p. 262). À Platão, portanto, não se deve, caricatamente, atribuir o rótulo do filósofo que de tanto olhar para as nuvens tropeça no mundo. Ao contrário, ele busca na Ideia, no Modelo uma forma de ordenar o mundo no qual muitos de seus contemporâneos tropeçavam. Ainda que considerado por Deleuze como filósofo da representação, da imagem do pensamento, Platão não era alheio aos problemas, sobretudo políticos, da Atenas da sua época. 
A diferenciação produzida por Platão entre os pretendentes a governante busca revelar os simulacros que tenderiam a vagar sem pátria, sem território. Desmerecedores de um espaço. Bastardos e desmoralizados estariam marcados como pretendentes ignóbeis, sub candidatos derrotados, "[...] construídos a partir de uma dissimilitude, implicando uma perversão, um desvio essenciais." (Deleuze, 1974, p. 262). O simulacro é o perdedor, é a diferença. Mas isso é justamente o que interessa para Deleuze e seu projeto filosófico da diferença.

O simulacro está proibido de se aproximar do governo dos homens. Em se tratando de cidadãos dispostos a ocupar a posição de pastor dos homens há uma gama vasta. “... mas muita gente se apresenta comerciantes, lavradores, pedreiros, ginastas, médicos, dizendo: o verdadeiro pastor de homens sou eu!" (Deleuze, 2018, p. 67). Esses pretendentes, ainda que ávidos pela governança sucumbem, um a um, diante do crivo objetivo da Ideia, do Modelo. Sua natureza de simulacro, de pretendente falso é negada.

Mas o problema maior é a ironia daqueles que surgem para criticar a validade da Ideia, do Modelo. E como fazem isso, senão através do sarcasmo, dos exemplos, das respostas esquivas, da habilidade retórica que persuade. Esse falso pretendente perigoso, que ronda a ágora é o Sofista. O grande adversário de Sócrates e também de Platão. Ele deve ser excluído. Sua entrada deve ser proibida na cidade ideal.

\section{A importância do mito no Platão de Deleuze}

Para entendermos as pretensões de Platão, Deleuze nos chama atenção primeiro para seu método de divisão. Pois nela, há uma clara intenção de decompor e não de agrupar (Deleuze, 1974, p. 261). Essa divisão, por sua vez, refere-se à separação, à diferenciação já que, a rigor, Platão trata de separar linhagens, distinguindo cópia e simulacro. Sem dúvida, Platão lança mão de uma dialética, e isso é confirmado por Deleuze. Entretanto, o filósofo francês defende a ideia de que essa é uma dialética dos rivais e não da contrariedade (Deleuze, 1974, p. 262). Os 
pretendentes que serão distinguidos entre verdadeiros e falsos de acordo com sua semelhança com a Ideia, com o Modelo, são, acima de tudo, rivais que disputam entre si.

Acontece que a certa altura dessa divisão Platão inclui um mito. No caso do Político aquilo que é narrado aponta para os tempos arcaicos, de criação do mundo, dos homens e das técnicas. Desse modo, o mito reaparece como potência porque vem superar a dualidade entre o mito e a dialética enquanto caminhos opostos, porém usados pelo método da divisão. Nesse sentido, a narrativa mítica ocupa o lugar do termo médio no silogismo lógico como queria Aristóteles. E assim: "É ele que permite erigir um modelo segundo o qual os diferentes pretendentes poderão ser julgados." (Deleuze, 1974, p. 261). O mito não é, portanto, recurso estilístico, tampouco é a falta de algo como propunha e criticava Aristóteles ao tomar como referência o termo médio do silogismo lógico. O mito é usado como Modelo. Sua função é medir os pretendentes. Anunciar seu grau de participação com a Ideia e assim esclarecer qual dos pretendentes deve ser, no caso do Político, o pastor dos homens.

No Político, o mito do pastor divino aparece através da fala do personagem do estrangeiro:

Mas a meu ver, Sócrates, essa figura do pastor divino é ainda muito elevada para um rei; os políticos de hoje, sendo por nascimento muito semelhantes a seus súditos, aproximam-se deles, ainda mais, pela educação e instrução que recebem. (PLATÃO, 275c).

Fica claro aqui que o mito ocupa o lugar do imparticipável. Tal como é a própria justiça. O pastor divino, como conta a narrativa, é a Ideia, o Modelo que servirá como padrão para a seleção das linhagens de pretendentes. Dele a cópia guardará alguma semelhança. Mas jamais será idêntica. O rei humano, portanto, nasce igual a seus súditos. E através de um processo longo onde adquire um aprendizado ele se distinguirá dos seus súditos que, em um procedimento de seleção diante do Modelo, ficariam relegados a simulacros e, assim, excluídos da possibilidade de se tornar pastor dos homens (governante). É por isso que Deleuze afirma: “... o fundamento é instituído no mito como princípio de 
uma prova ou de uma seleção, que dá todo seu sentido ao método da divisão, fixando os graus de uma participação eletiva." (Deleuze, 2018, p. 68). O mito é critério. É ele que dá conta, como último e irrecusável recurso para o objetivo de Platão que é fazer passar tudo e todos (os pretendentes) pelo crivo objetivo e inquestionável da Ideia, do Modelo.

Observemos que, no Platão de Deleuze, o mito não adorna o diálogo. Sua função é esclarecer na medida em que surge como lâmina afiada para cortar e separar os falsos dos verdadeiros pretendentes. Além disso, como pode falsamente parecer, o mito não é um recurso facilitador criado por Platão a fim de usá-lo com o intuito pedagógico. Em outros termos, o mito não está subjugado a uma função de fazer compreender-se sua filosofia e seu método de divisão de forma mais simples ou lúdica. Para Deleuze, Platão não brinca com o mito. Leva-o a sério, modifica-o, caso seja necessário, mas tudo com vistas a legitimá-lo como critério, como Modelo; como recurso inexorável com “... o propósito de isolar o falso pretendente por excelência, aquele que a tudo pretende sem qualquer direito: o "sofista"." (Deleuze, 2018, p. 68)

\section{Conclusão}

Falar dos simulacros e incluí-los em um projeto como o da filosofia da diferença, exigiu um esforço contínuo de Deleuze para esquivar de Platão (se é que isso seja admissível para qualquer pensador nos limites da filosofia), o que significa não hastear a bandeira da representação cujo mastro está fincado no território da imagem do pensamento. Por isso, a hipótese de que há um Platão de Deleuze. Ou seja, uma parte da filosofia criada por Platão interessa ao filósofo francês que a torce, a subverte de modo que lhe seja apropriada para fazer uma crítica ao pensamento de Platão a partir da criação de uma filosofia que exalte a repetição da diferença e o pensamento sem imagem. Ao ressaltar o simulacro, Deleuze expressa sua força. Retira-o da condição de fraqueza que a exclusão lhe impingiu. Há uma potência no simulacro ligada a repetição da diferença, 
pensada a partir da afirmação de que "Repetição não é generalidade." (Deleuze, 2018, p. 11).

Por isso, falar do Platão de Deleuze requer uma apresentação do problema, político e democrático da Atenas do século IV a.C. além de uma explicação da Ideia, do Modelo como uma ferramenta prática usada a fim de selecionar linhagens, na medida em que os pretendes ao governo dos homens eram tão diversos quanto perigosos. Platão quer afastar dos sofistas a chance de participar do Modelo, por isso os relega a falsos pretendentes, simulacros; sequer são cópias, ou seja, pretendentes legítimos.

A Deleuze e a sua filosofia da diferença interessam os simulacros porque guardam em seu interior a dessemelhança. Mas onde estão esses pretendentes que Platão chamou de falsos e expulsou da cidade? Ficaram sem pátria, sem espaço? Deleuze cria uma geografia do pensamento, com o intuito de inventar para os simulacros um espaço de existência: o espaço do pensamento sem imagem. É para lá que o filósofo francês carrega os dessemelhantes. Aqueles que repetem o outro.

Vejamos: se para Deleuze o que interessa é a reprodução do outro através da diferença, não poderia ele também reproduzir Platão para criar ou usar um mesmo Platão. O Platão de Deleuze é outro. E é a filosofia da diferença quem legitima seu procedimento. Mas, se não conhecemos seu projeto filosófico negamos Deleuze. Negamos que Deleuze possa ter criado seu próprio Platão.

\section{Referências:}

CUNHA, M. H. L. Nietzsche - Espírito artístico. Londrina: Edições CEFIL, 2003.

CUNHA, M. H. L. Rhizoma: Uma estética da existência em Platão, Nietzsche e Jung. Teresópolis: Ed. Verbete, 2009.

DELEUZE, G \& GUATTARI, F. O que é a filosofia? Trad. Bento Prado Jr. E Alberto Alonso Muñoz. Rio de Janeiro: Ed.: 34, 1992.

DELEUZE, G. Diferença e repetição. Trad. Roberto Machado e Luiz Orlandi. São Paulo: Ed. Paz e Terra, 2018.

DELEUZE, G. Lógica dos sentidos. Trad. Luiz Roberto Salinas Fortes. São Paulo: Ed.: Perspectiva. 1974. 
DELEUZE, G. $O$ ato de criação. Trad. José Marcos Macedo. São Paulo. Edição brasileira, in: Folha de S. Paulo, 27/06/1999.

NIETSZCHE, F. Além do bem e do mal. Trad. Lilian Salles Kump. São Paulo: Ed. Centauro. 2006.

NIETZSCHE, F. Crepúsculo dos ídolos: Como filosofar com o martelo. Trad. Jacqueline Valpassos. São Paulo: Editora DPL. 2009.

PERINE, M. Platão não estava doente. São Paulo: Edições Loyola. 2014

PLATÃO. Político. Trad. Jorge Paleikat e João Cruz Costa. São Paulo: Ed. Abril Cultural. 1972.

PLATÃO. República. Tradução Maria Helena da Rocha Pereira. 9. ed. Lisboa: Fundação Calouste Gulbbenkian, 2001. 
